\title{
Entorhino-subicular lesions: Amnestic effects on an assortment of learned responses in the white rat
}

\author{
ROBERT THOMPSON \\ Louisiana State University, Baton Rouge, Louisiana 70803
}

\begin{abstract}
Rats previously trained on a brightness discrimination habit, incline plane discrimination problem, maze habit, or an active avoidance conditioned response showed significant retention deficits following bilateral electrolytic lesions to the entorhino-subicular area. It would appear that the entorhino-subicular are must be included within the "general memory system" (along with the brainstem reticular formation) by virtue of its contribution to the expression of a wide variety of learned responses.
\end{abstract}

It has been reported that discrete lesions damaging regions of the brainstem which roughly parallel the trajectory of the ascending reticular activating system produce retention deficits on a wide variety of learned responses in the rat, including visual and nonvisual discrimination habits, a conditioned avoidance response, and a maze habit (Thompson, 1974, 1976; Thompson \& Thorne, 1973). The specific structures composing this broad brainstem region (ventral portions of the pontine and midbrain reticular formation, red nucleus, substantia nigra, ventral tegmental area, posterior thalamus, posterolateral hypothalamus, subthalamus, entopeduncular area, and the caudal portions of the corpus striatum) have been conceived to constitute the main components of a neural complex, termed the "general memory system," that plays a role in the expression of most learned habits acquired by the albino rat.

According to the results of the current study, the entorhino-subicular area must also be included within this general memory system.

\section{METHOD}

Thirty-two adult male albino rats of the Wistar strain were trained on a brightness discrimination habit (approach a white card and avoid an adjacent black card), an incline plane discrimination problem (choose an upward sloping arm and avoid an adjacent downward sloping arm in a single-unit T-maze), a 3-cul maze habit, or an active avoidance conditioned response. The training procedure used in connection with the brightness discrimination habit was the same as that described by Thompson, Chetta, and LeDoux (1974). The training procedures used to study the inclined plane problem and the maze habit were the same as those reported in Thompson and Thorne (1973) and Thompson (1974), respectively. The training procedure involved in the investigation of the active avoidance response has not been previously described and, therefore, requires some attention. The apparatus, which was similar to that described by Maatsch (1959), consisted of a box with a grid floor and a ledge rimming the perimeter of the box. In this situation, the rat was trained to jump onto the ledge within $10 \mathrm{sec}$ in order to avoid

This research was supported in part by a grant from the Graduate Council on Research, Louisiana State University. footshock. (Shock intensity averaged $2.5 \mathrm{~mA}$.) If the animal failed to make the jumping response within $10 \mathrm{sec}$ (error), footshocks were administered at a rate of about one every 2 sec until the appropriate response was made. One trial was given daily until the animal made at least three avoidance responses within 4 successive days.

Following learning, half of the rats sustained bilateral electrolytic lesions to the entorhino-subicular area (using the dorsal approach), while the remaining half served as normal controls. After a 2-week recovery (or rest) period, each animal was required to relearn the problem that was mastered preoperatively. Error savings scores constituted the measure of retention.

Following the retention test, histological verification of the locus and extent of the lesions was carried out. Details of the surgical and histological procedures have been reported elsewhere (Thompson, 1971).

\section{RESULTS}

For each task, data were obtained on four operated and four control subjects. The mean number of errors committed during original learning of the brightness, incline plane, maze, and avoidance habits was 11.5 , $20.0,15.5$, and 3.5 , respectively.

Table 1 shows the error savings scores for all groups. It will be noted that the savings scores earned by the operated animals were significantly inferior to those of the controls on each of the four problems studied. The greatest deficit occurred on the avoidance habit (none of the operated animals reached the criterion of learning within 10 days-training was terminated at this point), the smallest deficits on the discrimination habits, and an intermediate deficit on the maze habit.

Table 1

Mean Percentage Error Savings Scores for all Groups

\begin{tabular}{lcccc} 
Group & Brightness & $\begin{array}{c}\text { Incline } \\
\text { Plane }\end{array}$ & Maze & Avoidance \\
\hline Control & 100 & 95.2 & 97.5 & 100 \\
Operated & $21.2^{*}$ & $25.0^{*}$ & $-28.8^{*}$ & $-237.5^{*}$ \\
\hline
\end{tabular}

*Differed from the controls at least at the .05 level (MannWhitney test). 


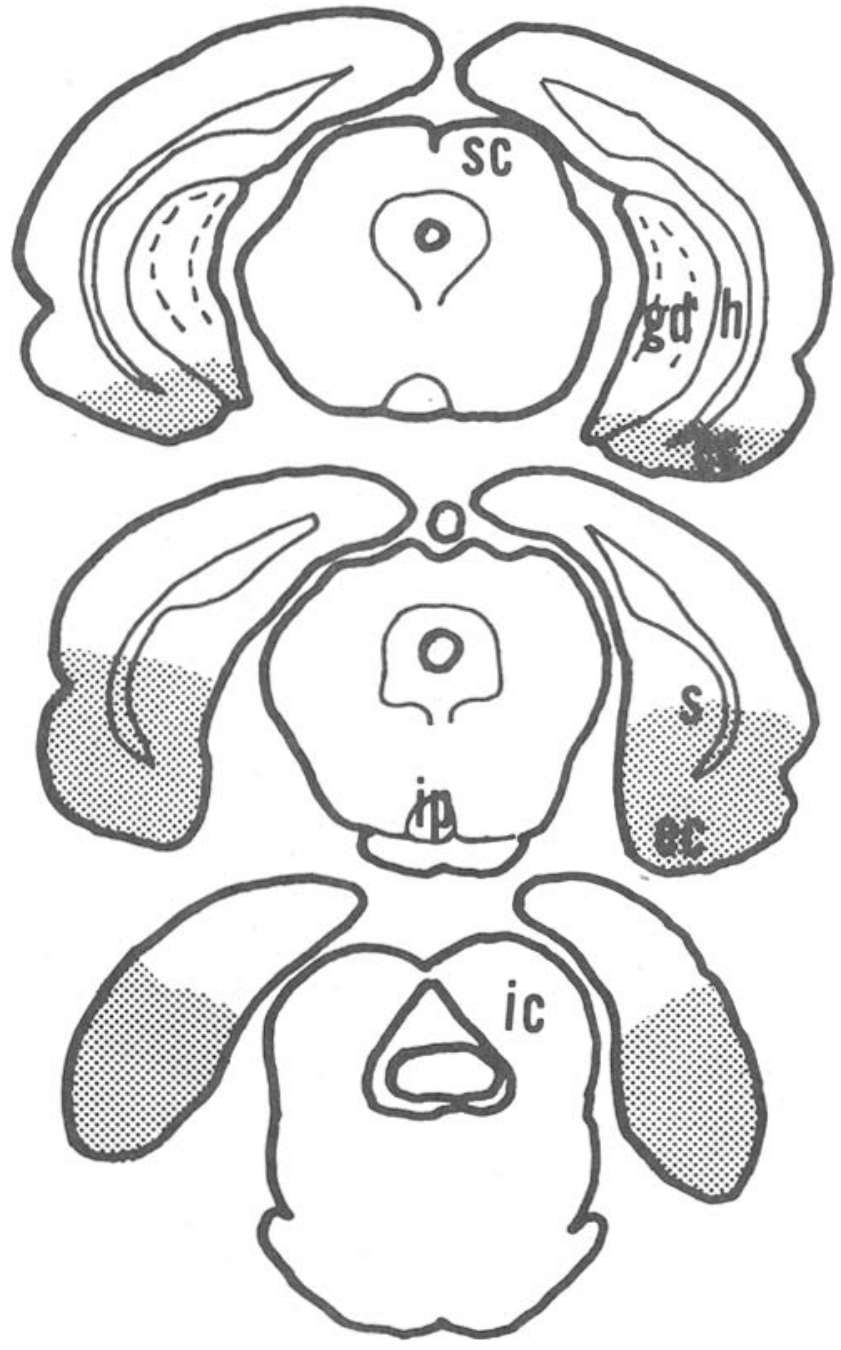

Figure 1. A typical lesion (shaded area) to the entorhinosubicular area. (Abbreviations: ec $=$ entorhinal cortex. gd = dentate gyrus, $h=$ hippocampus, ic = inferior colliculus, ip $=$ interpeduncular nucleus, $s=$ subiculum, $s c=$ superior colliculus).

Figure 1 shows a representative lesion to the entorhino-subicular area. Although the number of operated animals within each group was small, there was a trend in the data suggesting that the magnitude of the retention deficit on each problem was directly related to the size of the lesion.

Ancillary behavioral observations revealed that the operated animals tended to be hyperactive and/or hyper- exploratory, hypersensitive to footshock, and aggressive toward their cage mates and toward the experimenter.

\section{DISCUSSION}

On the strength of the foregoing findings, it is clear that the entorhino-subicular area must be included within the general memory system to the extent that destruction of this area interferes with the expression of a variety of learned responses. As pointed out earlier (Thompson, 1976; Thompson and Thorne, 1973), the various components of the general memory system appear to be related to the brainstem reticular formation. The inclusion of the entorhino-subicular area within this system may not require a revision of this view, as suggested by the work of Adey and 'his associates (Adey, 1958; Adey, Dunlop, \& Sunderland, 1958) on the interrelationships between the entorhinal cortex and the brainstem reticular formation.

Since the hippocampus has both afferent and efferent connections with the entorhinal area, it would seem reasonable to suppose that the former structure would also be a component of the general memory system. While this may indeed turn out to be the case, lesion studies have not been able to reveal a critical role of the hippocampus in the expression of visual and incline plane discrimination habits (Thompson, 1976; Truax \& Thompson, 1969). If future investigations continue to implicate the entorhino-subicular area in visual and nonvisual discrimination performance, but fail to implicate the hippocampus in the performance of these tasks, then the possibility that some portion of the rodent's entorhino-subicular area is homologous with the primate's inferotemporal cortex must be considered.

\section{REFERENCES}

ADEY, W. R. Organization of the rhinencephalon. In H. H. Jasper (Ed.), Reticular formation of the brain. Boston: Little, Brown, 1958.

Adey, W. R., Dunlop, C. W., \& Sunderland, S. A survey of rhinencephalic interconnections with the brain stem. Journal of Comparative Neurology, 1958, 110, 173-203.

MaATSCH, J. L. Learning and fixation after a single shock trial. Journal of Comparative and Physiological Psychology, 1959. 52, 408-410.

Tномрson, R. Introducing subcortical lesions by electrolytic methods. In R. D. Myers (Ed.), Methods in psychobiology. New York: Academic Press, 1971.

Thомpson, R. Localization of the "maze memory system" in the white rat. Physiological Psychology, 1974, 2, 1-17.

Tномрson, R. Stereotaxic mapping of brainstem areas critical for memory of visual discrimination habits in the rat. Physiological Psychology, 1976, 4, 1-10.

Thompson, R., Chetta, H., \& LeDoux, J. E. Brightness discrimination loss after lesions of the corpus striatum in the white rat Bulletin of the Psychonomic Society, 1974, 3, 293-295.

ThOMpson, R., \& ThORNE, B. M. Brainstem reticular formation lesions: Amnestic effects on learned habits in the rat. Physiological Psychology, 1973, 1, 61-70.

Truax, T., \& Thompson, R. Role of the hippocampus in performance of easy and difficult visual discrimination tasks. Journal of Comparative and Physiological Psychology, 1969. 67. 228-234.

(Received for publication July $30,1976$. ) 